\title{
Shortfall in mental health service utilisation
}

\author{
GAVIN ANDREWS, CATHY ISSAKIDIS and GREG CARTER
}

\author{
Background Treatment coverage \\ for mental disorders is poor in most \\ developed countries.
}

\begin{abstract}
Aims To explore some reasons for the poor treatment coverage for mental disorders in developed countries.
\end{abstract}

Method Datawere taken from Australian national surveys and from the World Health Report.

Results Onlyone-third of people with a mental disorder consulted. Probability of consulting varied by diagnosis: $90 \%$ for schizophrenia, which is accounted for by external factors; $60 \%$ for depression; and $15 \%$ for substance use and personality disorders. The probability of consulting varied by gender, age, marital status and disability, from $73 \%$ among women aged 25-54 years, disabled and once married to $9 \%$ among males without these risk factors. Those who did not consult but were disabled or comorbid said that they "preferred to manage themselves". Data from five countries showed no evidence that overall health expenditure, out-ofpocket cost or responsiveness of the health system affected the overall consulting rates.

Conclusions Societal, attitudinal and diagnostic variables account for the variation. Funding does not. Public education about the recognition and treatment of mental disorders and the provision of effective treatment by providers might remedy the shortfall.

Declaration of interest None. Funding detailed in Acknowledgements.
Mental disorders account for $22 \%$ of the total burden of disease in established market economies (Murray \& Lopez, 1996) and yet less than one-third of people with mental disorders consult and even fewer receive the effective treatments that are available (Andrews \& Henderson, 2000). As always, coverage, clinician competence and patient compliance are the cornerstones of strategies to reduce the burden of a disease (Andrews et al, 2000). Is the probability of consulting a function of the richness or accessibility of the health system, or is it a function of attributes of the individual or of the illness from which they suffer? We will focus mainly on data from the Australian national mental health survey to examine these questions (Andrews et al, 2001). Australia has a hybrid publicprivate system that makes most primary and mental health specialist services free at the point of delivery, a system that is midway between the UK, Canadian, New Zealand and US systems. Although specific to Australia, these data are relevant to other countries.

\section{METHOD}

The details of the survey and the primary results have been described previously (Andrews et al, 2001). A national probability sample of Australian households was surveyed and $78 \%$ of those approached (10 641 adults aged 18 years and over) responded. Interviewers administered a computerised interview that included the Composite International Diagnostic Interview (Andrews \& Peters, 1998) to identify symptoms within the past 12 months that satisfied criteria for the common anxiety, affective and substance use disorders in both the ICD and DSM classifications. The DSM-IV classification (exclusion criteria not operationalised) is used here (American Psychiatric Association, 1994). Screening interviews were used for psychosis (Cooper et al, 1998), somatoform disorder (neurasthenia), cognitive impairment and personality disorder (Slade et al, 1998) and for the presence of chronic physical conditions. The interview also contained a neuroticism scale (Eysenck et al, 1985), a disability measure (SF-12; Ware et al, 1996), a service utilisation questionnaire (Carter, 1998) and a perceived need for care questionnaire (Meadows et al, 2000).

\section{Analysis \\ Dependent variables}

Three planned analyses were conducted to examine service utilisation and type of treatment received (see Fig. 1).

(a) Service utilisation in the whole sample ( $n=10$ 641): the dependent variable used was one or more consultations for mental health problems with any health professional $v$. none.

(b) Service utilisation among respondents with a current disorder $(n=1422)$ : the dependent variable used was one or more consultations for mental health problems with any health professional $v$. none.

(c) Perceived need for care among respondents with a current disorder who did not seek treatment $(n=836)$ : the dependent variable used was any perceived need for treatment $v$. none.

In the text, therefore, 'mental health consultations' refer to all consultations for mental health problems regardless of the type of health professional consulted.

\section{Coding of mental disorders}

For analysis of service utilisation in the whole sample, DSM-IV mental disorders were coded in three levels: 'no disorder', 'sub-threshold disorder' (i.e. answered yes to criterion A questions but failed subsequent criteria) and 'met full criteria for disorder'. Respondents who met the criteria for at least one DSM-IV mental disorder were coded against their principal current disorder, that is, respondents were coded against their only disorder when they met the criteria for one disorder or against the disorder "that troubled them the most" where respondents met the criteria for more than one disorder. This coding strategy ensured that service use for mental health problems was counted against the respondent's most clinically significant mental disorder and that no person was counted twice. Psychosis and cognitive impairment 


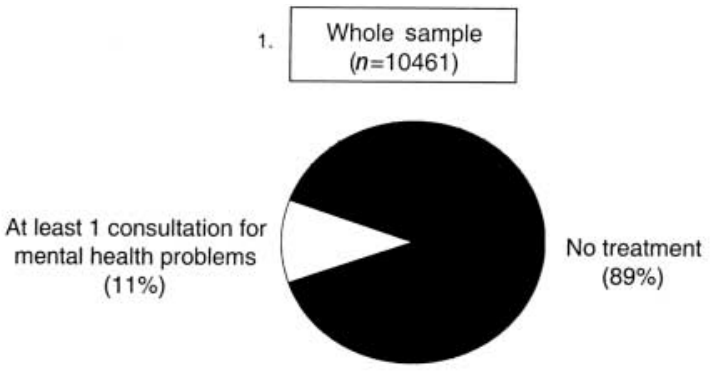

2. Current principal mental disorder
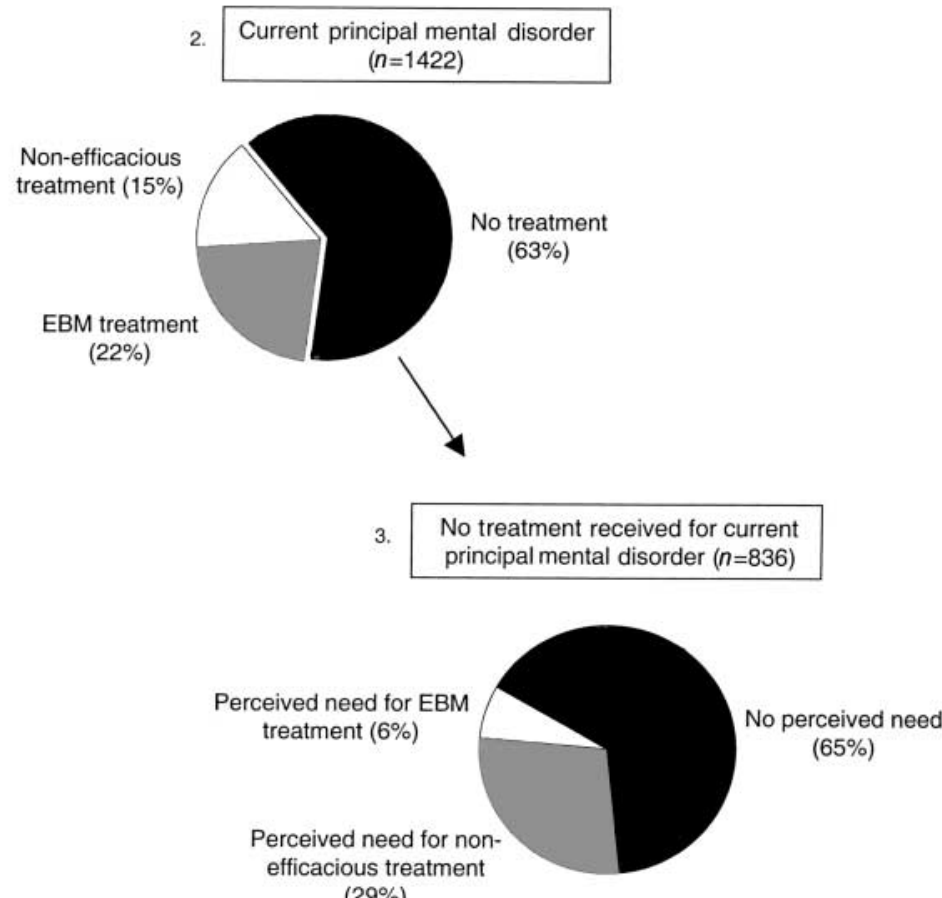

(29\%)

Fig. I Service utilisation for mental health problems and perceived need for care in the whole sample and among persons with a current DSM-IV disorder. EBM, evidence-based medicine: here, medication or cognitive-behavioural therapy.

were included in the calculation of service utilisation for any mental disorder $(n=$ 2352; Tables 1 and 2) and they were not included in subsequent analyses. Data on a larger sample of persons with psychosis are available from the parallel Low Prevalence Disorders Survey (Jablensky et al, 2000).

\section{Calculation of odds ratios}

Odds ratios (ORs) were calculated from logistic regression models with dependent variables as described above. Standard errors around proportions and confidence intervals around ORs were calculated using jackknife repeated replication to account for the complex survey design (Kish \& Frankel, 1974). The SUDAAN software package, designed for use with complex survey samples, was used for these calculations (Shah et al, 1997).

\section{Model-building processes}

For each regression model, independent variables were examined in three groups: socio-demographic correlates; disability and neuroticism; and mental and physical disorders. The first stage of the analysis examined each group of variables separately to determine their contribution to each model. Any variable that did not contribute significantly to the model fit $(P<0.05)$ was eliminated from further analyses. In the second stage of the analysis, significant variables from each group were entered into a final model so that the effects of each variable could be examined after controlling for all other significant variables. All models that contained mental disorders as independent variables controlled for the presence of physical disorders. The regression coefficients from the model for the principal complaint then were used to calculate the predicted probability of consulting among different risk groups (see Fig. 2).

\section{RESULTS}

\section{Service utilisation in the whole sample ( $n=10$ 64I; Fig. I, box I)}

Service utilisation and treatment received is presented in Table 1. One-ninth of the Australian population had seen a health professional at least once for a mental health problem in the 12 months prior to interview. One-third of those who met the criteria for at least one mental disorder during the year had consulted (an average of eight times) but only one in nine had seen a mental health professional. Consultations for mental health problems among respondents with a sub-threshold mental disorder or no mental disorder were considerably lower $(10.6 \%$ and $2.8 \%$, respectively) and $77 \%$ of all consultations for a mental health problem were with people who met the criteria for a mental disorder. Although unmet need was considerable, inappropriate consulting among well people was not.

More than half $(61 \%)$ of those with a mental disorder who sought treatment for mental health problems reported receiving medication or tablets and $57 \%$ reported non-specific counselling ("help to talk through your problems"). People with sub-threshold or without disorder were treated similarly, as though a "prescription and a chat" was the stock in trade of doctors being consulted for a mental health problem, whether or not the person met the criteria for a diagnosis. Correlates of treatment-seeking in the whole sample are presented in Table 2 .

\section{Socio-demographic correlates}

Women were more likely to consult than men $(\mathrm{OR}=1.90)$, those aged 25-54 years compared with those aged 18-24 years $(\mathrm{OR}=1.84-2.32)$ and persons who were previously married (separated, widowed or divorced) compared with persons in a married or de facto relationship $(\mathrm{OR}=$ 1.42). Less education was associated with service use $(\mathrm{OR}=0.54-0.57)$. Employment status was a significant correlate of service use in early analyses but was not significant once the model controlled for disability, neuroticism and mental disorders. 


\begin{tabular}{|c|c|c|c|c|}
\hline & \multicolumn{4}{|c|}{ Presence of sub-threshold or criteria DSM-IV disorder } \\
\hline & $\begin{array}{l}\text { Any mental disorder' } \\
\qquad(n=2352)\end{array}$ & $\begin{array}{l}\text { Any sub-threshold mental disorder } \\
\qquad(n=2575)\end{array}$ & $\begin{array}{l}\text { No mental disorder } \\
\qquad(n=57 / 4)\end{array}$ & $\begin{array}{c}\text { Total } \\
(n=10641)\end{array}$ \\
\hline \multicolumn{5}{|l|}{ Type of health professional (\% (s.e.)) } \\
\hline General practitioner only² & $11.6(0.9)$ & $5.6(0.7)$ & $1.3(0.2)$ & $4.5(0.2)$ \\
\hline Mental health professional ${ }^{3}$ & II.I (0.7) & $1.9(0.3)$ & $0.5(0.1)$ & $3.1(0.2)$ \\
\hline Other health professional ${ }^{4}$ & $9.8(0.8)$ & $3.2(0.4)$ & $1.0(0.2)$ & $3.4(0.2)$ \\
\hline Any health professional & $32.5(0.9)$ & $10.6(0.9)$ & $2.8(0.4)$ & II.I (0.3) \\
\hline \multicolumn{5}{|l|}{ Number of contacts } \\
\hline Mean number of $\operatorname{contacts}^{5}(\bar{x}($ s.e. $))$ & $7.8(0.3)$ & $3.9(0.3)$ & $4.2(0.5)$ & $6.4(0.2)$ \\
\hline Proportion of total population contacts ${ }^{6}(\%)$ & 76.9 & 14.1 & 9.0 & 100 \\
\hline \multicolumn{5}{|l|}{ Type of intervention (\% (s.e.)) } \\
\hline Information about illness and treatment & $32.8(2.6)$ & $12.0(2.5)$ & $12.9(3.2)$ & $25.2(1.6)$ \\
\hline Medicine or tablets & $61.0(3.6)$ & $48.0(3.3)$ & $46.0(4.8)$ & $56.0(2.8)$ \\
\hline Psychotherapy & $18.8(1.5)$ & $7.5(1.7)$ & $8.0(3.1)$ & $14.7(1.1)$ \\
\hline Cognitive-behavioural therapy & $17.9(1.5)$ & $4.8(1.9)$ & $6.3(2.0)$ & $13.3(1.0)$ \\
\hline Non-specific counselling & $56.7(2.7)$ & $45.7(3.3)$ & $39.2(4.8)$ & $51.7(2.3)$ \\
\hline Social support & $20.0(1.2)$ & II.8 (2.8) & $8.6(2.2)$ & $16.6(1.0)$ \\
\hline \multicolumn{5}{|c|}{$\begin{array}{l}\text { 1. Met DSM-IV criteria for any affective, anxiety, substance use, personality and somatoform disorders, cognitive impairment and psychosis any time during the previous } 12 \text { months. } \\
\text { 2. Respondents saw a general practitioner but did not see any other health professional for mental health problems. } \\
\text { 3. Respondents saw a psychiatrist, psychologist or mental health team for mental health problems and may or may not have seen another health professional. } \\
\text { 4. Respondents saw a welfare worker or other counsellor or a non-psychiatric medical specialist for mental health problems but did not see a mental health specialist. } \\
\text { 5. The mean is computed only for respondents who had at least one contact with a health professional for mental health problems. } \\
\text { 6. The weighted total number of contacts for the entire sample ( } n=10641) \text { was computed. This total then was divided across each disorder category. } \\
\text { 7. Percentages are calculated only for respondents who had at least one consultation with a health professional for mental health problems. Respondents could specify more than one } \\
\text { type of treatment. }\end{array}$} \\
\hline
\end{tabular}

\section{Disability and neuroticism}

Higher levels of disability (or lower levels of functioning) on both the physical and the mental health scale of the SF-12 were associated with consultation for mental health problems $(\mathrm{OR}=0.87$ and 0.63 , respectively). Even so, only $52 \%$ of people with a disorder and moderate or severe disability $(\mathrm{SF}-12<40)$ consulted for a mental problem.

\section{Mental disorders}

The odds ratios for consulting for subthreshold and full-criteria disorders were 2.93 and 7.83 , respectively. When the relationship between probability of mental health consultation and type of disorder was examined, the presence of both subthreshold and full-criteria disorders was significantly associated with service use for anxiety and affective disorders but not for substance use disorders or somatoform disorder. Personality disorders were not associated with service use in earlier analyses $\left(\chi^{2}=2.68, P=0.262\right)$ and therefore they were not included in the final model. Comorbidity, measured by the number of disorders for which respondents met the criteria, was significantly and independently associated with service utilisation for mental health problems $\left(\chi^{2}=454.4\right.$, $P<0.001)$ and odds ratios increased with the number of disorders. The presence of a physical disorder was not significant in any of the models tested.

The regression coefficients from the model were used to define the probability of consulting for a mental health problem. Risk factors for consulting identified in the model were added in descending order of importance. The lowest predicted consulting rates were $5 \%$ for males under 24 or over 55 years, who had only one disorder, no disability, lower neuroticism, no physical health disability, were married or never married and not educated beyond high school. The highest rates $(91 \%)$ were in females aged 25-54 years in whom all the above risk factors were present.

\section{Service utilisation among those with a current principal disorder ( $n=$ 1422, Fig. I, box 2)}

Comorbidity, with other mental disorders and/or with physical disorders, was not uncommon. We wanted to explore service use with respect to the clinically significant disorder for which people would seek help. Box 2 of Fig. 1 therefore illustrates the treatment of people with current symptoms who, if they met the criteria for more than one disorder, identified their main disorder as the one that "troubled them the most". Cases of psychosis and cognitive impairment (prevalences of $0.4 \%$ and $1.3 \%$, respectively) were included in the previous analysis but were deleted from this and subsequent analyses because we had doubts about their ability to identify their main disorder appropriately.

Half of those who met the criteria for a mental disorder during the year reported symptoms in the past month. Only $37 \%$ of these current cases had consulted for mental health problems in the 12 months prior to interview. Moreover, only one-fifth $(22 \%)$, reported receiving a treatment for which there is evidence of efficacy (medication or cognitive-behavioural treatment). Whether they actually received effective treatments and complied is not known. Sixty-five per cent of respondents who had not sought treatment for a current disorder said that they had no need. Only 6\% reported a need for treatments believed to 
Table 2 Multivariate correlates of service utilisation for mental health problems in the whole sample $(n=10641)$

\begin{tabular}{|c|c|c|c|}
\hline & \multicolumn{3}{|c|}{ Final model } \\
\hline & OR & & $95 \% \mathrm{Cl}$ \\
\hline \multicolumn{4}{|l|}{ Group I: Socio-demographics } \\
\hline \multicolumn{4}{|l|}{ Gender } \\
\hline Male & - & & - \\
\hline \multirow[t]{2}{*}{ Female } & 1.90 & $* *$ & $1.33-2.72$ \\
\hline & $\chi_{1}^{2}=13.37$ & & $P<0.001$ \\
\hline \multicolumn{4}{|l|}{ Age } \\
\hline $18-24$ & 1.00 & & - \\
\hline $25-34$ & 1.85 & $*$ & $1.31-2.63$ \\
\hline $35-44$ & 2.32 & ** & I.54-3.48 \\
\hline $45-54$ & 2.15 & $*$ & $\mathrm{I} .4 \mathrm{I}-3.27$ \\
\hline $55-64$ & $\mathrm{I} .44$ & & $0.99-2.09$ \\
\hline $65-74$ & 0.80 & & $0.50-1.55$ \\
\hline \multirow[t]{2}{*}{$>75$} & 0.61 & & $0.31-1.21$ \\
\hline & $\chi_{6}^{2}=61.55$ & & $P<0.001$ \\
\hline \multicolumn{4}{|l|}{ Marital status } \\
\hline Married/de facto & 1.00 & & - \\
\hline Separated/divorced/widowed & 1.42 & $*$ & $1.12-1.80$ \\
\hline \multirow[t]{2}{*}{ Never married } & I.II & & $0.70-1.80$ \\
\hline & $\chi_{2}^{2}=12.80$ & & $P=0.002$ \\
\hline \multicolumn{4}{|l|}{ Education } \\
\hline Bachelor degree or higher & 1.00 & & - \\
\hline Diploma & 0.68 & & $0.42-1.11$ \\
\hline Vocational qualification & 0.54 & $*$ & $0.37-0.79$ \\
\hline \multirow[t]{2}{*}{ High school only } & 0.57 & $*$ & $0.40-0.80$ \\
\hline & $\chi_{3}^{2}=17.67$ & & $P=0.001$ \\
\hline \multicolumn{4}{|l|}{ Employment status } \\
\hline Employed & 1.00 & & - \\
\hline Short-term unemployed & I. 17 & & $0.59-2.33$ \\
\hline Long-term unemployed & 0.64 & & $0.35-1.17$ \\
\hline \multirow[t]{2}{*}{ Not in the labour force } & 1.14 & & $0.87-1.48$ \\
\hline & $\chi_{3}^{2}=4.21$ & & $P=0.239$ \\
\hline
\end{tabular}

Group 2: Disability and neuroticism

SF-12 I2-item Short-Form health survey

Mental health scale

Physical health scale

Neuroticism

Eysenck Personality Questionnaire - Neuroticism score

$\begin{array}{ccc}0.63 & * * & 0.53-0.73 \\ \chi^{2}{ }_{1}=36.13 & & P<0.001 \\ 0.87 & * & 0.78-0.97 \\ \chi^{2}{ }_{1}=7.26 & & P=0.007\end{array}$

$\begin{array}{ccc}\mathrm{I} .33 & * & \mathrm{I} .14-\mathrm{I} .56 \\ \chi^{2}{ }_{\mathrm{I}}=13.67 & & P<0.00 \mathrm{I}\end{array}$

Group 3: Mental disorders

3a. Presence of disorder

No mental disorder

Sub-threshold mental disorder

At least I mental disorder

$\begin{array}{ccc}1.00 & & - \\ 2.93 & * * & 1.83-4.67 \\ 7.83 & * * & 5.76-10.64 \\ \chi_{2}^{2}=403.43 & & P<0.001\end{array}$

(continued) be efficacious, defined above as receiving either medication or cognitive-behavioural therapy (see Nathan \& Gorman, 1998).

Mental health consultations by those with current principal disorders are presented in Table 3. Consultation was highest among affective disorders $(66.8 \%)$ and lowest among substance use $(14.7 \%)$ and personality disorders $(\mathbf{1 9 . 1 \% )}$. Eighty per cent of all consultations were with people with anxiety and depressive disorders. Consultation with mental health professionals also was highest among those with affective disorders $(24.4 \%)$. The most common interventions reported across all disorders were medication and non-specific counselling, although one in five reported receiving cognitive-behavioural therapy and an equal number psychotherapy.

The number of mental health consultations in the year ranged from a mean of 9.3 for affective disorder to 6.6 for substance use disorders. All the distributions were skewed and the medians were lower. Ten per cent of the consultees utilised $37 \%$ of the services and averaged 26 visits per year, principally to psychiatrists. Eighty-six per cent of these high utilisers nominated anxiety or depression as their principal complaint.

\section{Socio-demographic correlates}

These were similar to those reported for the whole sample (Table 2). Women were more likely to consult than men $(\mathrm{OR}=1.60)$, those aged 25-54 years than those aged over 65 years $(\mathrm{OR}=3.23-3.97)$ and persons who were separated, widowed or divorced than those in a married or de facto relationship $(\mathrm{OR}=1.65)$. Although employment status showed a significant relationship in earlier models $\left(\chi^{2}=12.14, P=0.007\right)$, it was not significant once other variables were added to the model $\left(\chi^{2}=2.04\right.$, $P=0.564)$.

\section{Disability and neuroticism}

Greater disability on the SF-12 measure was associated with consulting for mental health problems. Neither physical disability nor neuroticism was significant in the final model $\left(\chi^{2}=2.52, P=0.113\right.$ and $\chi^{2}=2.99$, $P=0.084)$.

\section{Mental disorders}

Those with anxiety, personality or substance use disorders were all less likely to consult for mental health problems 


\section{Perceived need for care among those with a current principal disorder who did not seek treatment ( $n=836$, Fig. I, box 3 )}

People who met criteria for a mental disorder and who had not sought help were asked if they had perceived a need for treatment for their symptoms (Table 4). Perceived need for treatment was highest among affective disorders $(58 \%)$ and lowest among substance use disorders $(15 \%)$. The most commonly reported need was for counselling (this section of the interview grouped psychotherapy, cognitive-behavioural therapy and non-specific counselling together). The perceived need for medication was relatively low $(9.6 \%$ and $15.7 \%)$ in contrast to doctors' usual response when consulted for a mental problem. The correlates of perceived need for care among those who did not seek treatment are little different from those derived from the whole group (Table 3 ) and are available from the authors. Some of the 836 people who did not seek treatment did not have disorders that were disabling. We therefore suggest that health services should not be primarily concerned for such people and that the provision of written, videotaped or web-based self-help materials could suffice (Gould \& Clum, 1993).

\section{Respondents with disability or comorbidity with a perceived need for treatment}

A total of $314(36 \%)$ reported a perceived need for treatment and $62 \%$ of this group either met the criteria for more than one mental disorder and/or had moderate or severe disability (SF-12<40). These people should be a priority target of treatment. This 'disabled and comorbid' group was asked why, given seeing that they had specified some need for treatment, they did not get that treatment. Of those who did not get treatment but had identified medication as a need, $61 \%$ said they did not get it because they preferred to manage themselves. Of those who identified counselling as a need, $42 \%$ said they did not get it because they preferred to manage themselves. Independence or stoicism is a laudable trait unless it interferes with relief of a disabling disorder, in which case it is self-defeating.

\section{Respondents with disability or comorbidity} with no perceived need for treatment

Over 500 hundred people $(5 \%)$ from the total population surveyed met the criteria for a mental disorder, did not seek treatment years), gender (female), marital status (separated/divorced/widowed) and mental health disability score (SF-12<40). The probability of consulting for an affective was $67 \%$ and the predicted pre according to the presence of the abov factors. The predicted probabilities of consulting for all five groups of disorder when identified as a main complaint are shown in Fig. 2, with the difference that each risk factor makes added to the baseline. The addition of comorbidity, which is a strong determinant of consulting, makes little difference to the predicted probabilities in Fig. 2, presumably because the effect is now subsumed by disability. 
Table 3 Service utilisation for mental health problems by disorder type for current cases - those who met criteria for their principal disorder in the past month $(n=1422)$

\begin{tabular}{|c|c|c|c|c|c|c|}
\hline & \multicolumn{6}{|c|}{ Principal disorder } \\
\hline & $\begin{array}{l}\text { Affective disorder } \\
\qquad(n=343)\end{array}$ & $\begin{array}{l}\text { Anxiety disorder } \\
\qquad(n=457)\end{array}$ & $\begin{array}{l}\text { Substance use } \\
\text { disorder } \\
(n=262)\end{array}$ & $\begin{array}{l}\text { Personality } \\
\text { disorder } \\
(n=305)\end{array}$ & $\begin{array}{l}\text { Somatoform } \\
\text { disorder } \\
(n=55)\end{array}$ & $\begin{array}{c}\text { Any current } \\
\text { DSM-IV disorder } \\
(n=1422)\end{array}$ \\
\hline \multicolumn{7}{|l|}{ Type of health professional (\% (s.e.)) } \\
\hline General practitioner only ${ }^{2}$ & $25.4(2.8)$ & $13.6(2.3)$ & $5.9(1.9)$ & $6.9(4.4)$ & $17.6(6.1)$ & I3.I (I.2) \\
\hline Mental health professional ${ }^{3}$ & $24.4(3.5)$ & $16.7(2.4)$ & $3.8(1.5)$ & $5.8(1.4)$ & - & I3.I (I.2) \\
\hline Other health professional ${ }^{4}$ & $17.0(2.8)$ & $13.7(1.8)$ & $5.1(4.6)$ & $6.4(2.2)$ & - & $10.9(1.6)$ \\
\hline Any health professional & $66.8(3.5)$ & $44.0(2.0)$ & $14.7(4.4)$ & $19.1(3.1)$ & $46.2(9.0)$ & $37.1(1.7)$ \\
\hline \multicolumn{7}{|l|}{ Number of contacts } \\
\hline Mean number of contacts ${ }^{5}(\bar{x}($ s.e. $))$ & $9.3(0.6)$ & $9.1(0.7)$ & $6.6(1.3)$ & $6.9(0.8)$ & $7.8(2.0)$ & $8.7(0.3)$ \\
\hline Proportion of total population contacts ${ }^{6}(\%)$ & 41.1 & 38.8 & 6.0 & 4.3 & 9.8 & 100 \\
\hline \multicolumn{7}{|l|}{ Type of intervention ${ }^{7}$ (\% (s.e.)) } \\
\hline Information about illness and treatment & $25.9(3.8)$ & $28.9(2.9)$ & $24.0(8.3)$ & $27.5(9.5)$ & - & $26.4(2.5)$ \\
\hline Medicine or tablets & $58.7(6.2)$ & $52.9(5.1)$ & $27.8(5.1)$ & $43.9(10.6)$ & $43.2(13.0)$ & $51.6(3.3)$ \\
\hline Psychotherapy & $16.9(3.8)$ & $18.2(2.6)$ & - & $16.4(7.3)$ & - & $17.0(1.7)$ \\
\hline Cognitive-behavioural therapy & $17.2(3.8)$ & $21.3(3.1)$ & - & - & - & I7.7 (I.6) \\
\hline Non-specific counselling & $50.8(4.5)$ & $48.4(7.3)$ & $50.7(9.0)$ & $44.2(15.0)$ & - & $47.5(2.8)$ \\
\hline Social support & $10.1(1.9)$ & I7.I (2.7) & - & - & - & $12.6(1.0)$ \\
\hline
\end{tabular}

Note: Data are not presented where sample cell sizes are less than ten.

I. Does not include diagnoses of cognitive impairment or psychosis.

2. Respondents saw a general practitioner but did not see any other health professional for mental health problems.

3. Respondents saw a psychiatrist, psychologist or mental health team for mental health problems and may or may not have seen another health professional.

4. Respondents saw a welfare worker or other counsellor or a non-psychiatric medical specialist for mental health problems but did not see a mental health specialist.

5. The mean is computed only for respondents who had at least one contact with a health professional for mental health problems.

6. The weighted total number of contacts for the sample $(n=1346)$ was computed. This total then was divided across each disorder category.

7. Percentages were calculated only for respondents who had at least one contact with a health professional for mental health problems.

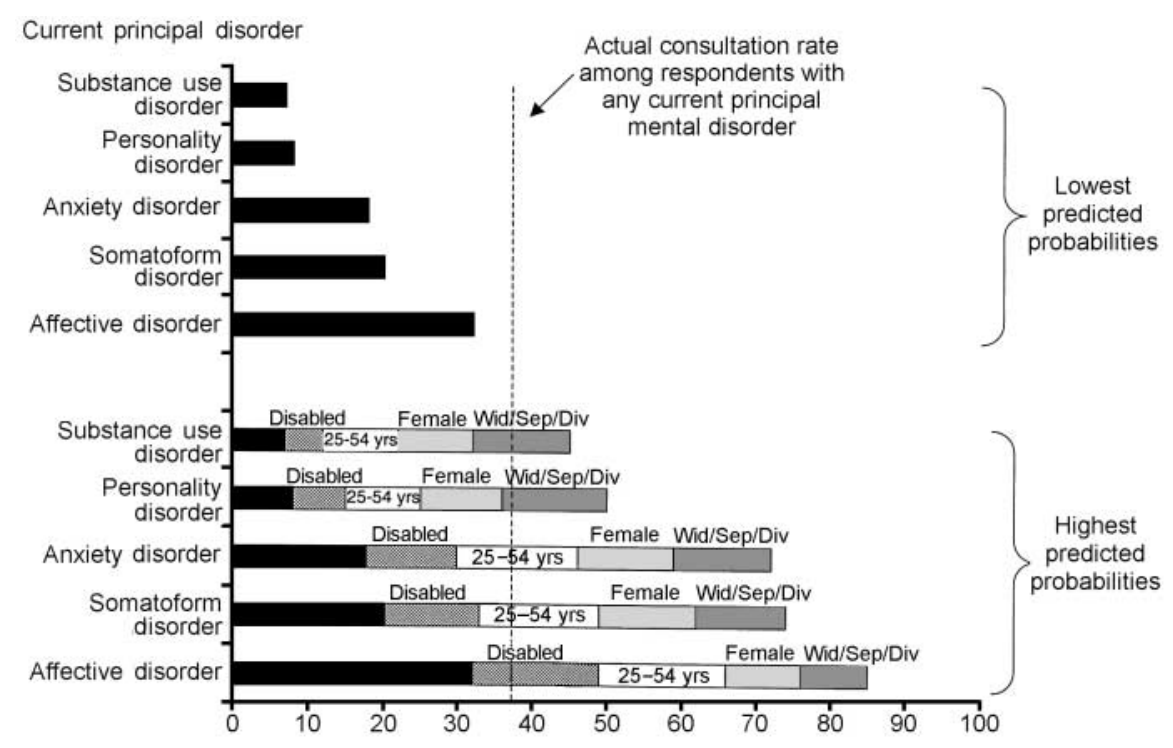

Fig. 2 Predicted probability of consulting for a mental health problem by current principal disorder type among different risk groups. Lowest predicted probabilities represent the probabilities of consulting among respondents with an affective, anxiety, substance use or personality disorder or neurasthenia as their principal complaint and none of the other risk factors (i.e. among males, aged 18-24 or over 55 years, either currently married or not previously married and with no mental-health-related disability). They therefore represent the lowest predicted probabilities for each disorder type. and said they had no need for treatment. Again, there were many who had no comorbidity or disability and self-help materials might well be appropriate for them. However, one-third (168/522) met the criteria for more than one disorder and/or had moderate or severe disability, reporting that they had been unable to work or had to cut down on what they did 6.6 days out of the previous 28 days. They, too, should be a target for treatment. Because they had not specified any need for treatment, we were unable to ask about the barriers to treatment, but we could compare their socio-demographic characteristics with the people with comorbidity and/or disability who had sought treatment. They were more likely to be males $\left(\chi^{2}=15.9\right.$, d.f. $=1$, $P<0.001)$ and under 24 or over 65 years $\left(\chi^{2}\right.$ for all levels of age $=11.9$, d.f. $=5$, $P=0.06)$ than the comparison group who had sought treatment.

\section{DISCUSSION}

In the total sample $32 \%$ of people who met the criteria for a mental disorder consulted 


\begin{tabular}{|c|c|c|c|c|c|c|}
\hline & \multicolumn{6}{|c|}{ Principal disorder } \\
\hline & $\begin{array}{l}\text { Affective disorder } \\
\qquad(n=I 10)\end{array}$ & $\begin{array}{l}\text { Anxiety disorder } \\
\qquad(n=242)\end{array}$ & $\begin{array}{l}\text { Substance use } \\
\text { disorder } \\
(n=220)\end{array}$ & $\begin{array}{l}\text { Personality } \\
\text { disorder } \\
(n=237)\end{array}$ & $\begin{array}{l}\text { Somatoform } \\
\text { disorder } \\
(n=27)\end{array}$ & $\begin{array}{c}\text { Any DSM-IV } \\
\text { disorder' } \\
(n=836)\end{array}$ \\
\hline \multicolumn{7}{|l|}{ Intervention type (\% (s.e.)) } \\
\hline Information about illness and treatment & $16.8(4.3)$ & $23.3(2.5)$ & $4.6(2.7)$ & II.3 (2.I) & - & $13.4(1.3)$ \\
\hline Medicine or tablets & $15.7(4.2)$ & $9.6(2.2)$ & - & $3.1(1.2)$ & - & $6.3(1.0)$ \\
\hline Counselling ${ }^{2}$ & $36.9(6.2)$ & $33.5(3.0)$ & $3.1(1.6)$ & $16.9(4.8)$ & - & $21.2(2.5)$ \\
\hline Social support ${ }^{3}$ & $28.0(7.2)$ & $19.6(2.1)$ & $7.6(2.9)$ & $14.6(2.3)$ & - & $15.7(1.4)$ \\
\hline Any perceived need & $58.2(5.2)$ & $52.4(3.2)$ & $14.8(3.7)$ & $30.3(3.6)$ & - & $35.3(1.9)$ \\
\hline
\end{tabular}

I. Does not include diagnoses of cognitive impairment or psychosis.

2. Includes psychotherapy, cognitive-behavioural therapy and non-specific counselling.

3. Includes help with finances, housing and welfare, as well as social support.

for a mental problem. Consulting was much less frequent in people with sub-threshold disorders or with no disorder, and $77 \%$ of all consultations occurred with people who met the criteria for a mental disorder. Medication and counselling were the most common treatments offered to all groups. In a multivariate model, consulting was more frequent in females, in people aged 24-54 years, in the educated, in people with high scores on disability and neuroticism scales and in people with anxiety, affective and to a lesser extent substance use disorders. Comorbidity also was associated with consultation.

We then analysed the patterns of consulting (except for psychosis and cognitive impairment) among those who met the criteria for a current disorder that they had identified as their principal complaint, comparing people who consulted with people who did not. Consultation rates were highest for affective and anxiety disorders, together accounting for $80 \%$ of all consultations for a mental problem by people who met the criteria for a mental disorder. We used the correlates of consulting to calculate a predicted probability among different risk groups. It ranged from a high of $85 \%$ among previously married women aged 25-54 years with an affective disorder and significant disability, to a low of $7 \%$ among married or never married males under 24 or over 65 years with a substance use disorder and mild disability. Medication and counselling were the treatments reported most commonly. Ten per cent, mainly people with anxiety and depression, accounted for $37 \%$ of all consultations and saw their doctor (often a psychiatrist) an average of 26 times a year. This may be evidence of a small group of patients being resistant to or non-compliant with effective treatments, being offered treatments that are not effective or some combination of these factors. It represents a reduction in service potential to other equally ill patients who might be expected to have a more prompt therapeutic response.

Nearly two-thirds of people with a current disorder did not consult and, although this might be acceptable for those without disability and comorbidity, it was not felt to be appropriate for the remainder. We therefore focused on this group of people with disability and/or comorbidity and had not sought treatment. We asked the people who expressed a need for treatment why they had not consulted and the majority said "I preferred to manage myself". We could not ask the people who had no perceived need why they did not get treatment but we did look at the demographics - being male and aged 1824 or over 65 years were the characteristics overrepresented.

\section{Threats to validity}

These data are based on self-report, both of the symptoms that could be matched against diagnostic criteria and of the responses to the question "Did you consult for a mental problem such as stress, anxiety, depression or dependence on drugs or alcohol?". The main problem is the screening interview used for psychosis (Cooper et al, 1998). In the present survey $43 \%$ of people identified by the psychosis screener reported a mental health consultation, and even if the true figure is double this, it would only add a further 22 people to those who consulted and would not affect the overall consulting rate.

\section{Effect of health system variables}

Can these data be explained by system variables that determine access to treatment? The World Health Report 2000 (World Health Organization, 2000) drew attention to the importance of system variables to health attainment - characteristics such as size of budget, responsiveness to patient needs and fairness in financing health care; these are all factors that determine the level of services available, the ease of access and availability to the poor. Alegria et al (2000) compared rates of consulting for a mental problem among people who met the criteria for a mental disorder in surveys in the USA, Canada and The Netherlands, three countries with quite distinct methods of financing health care. The USA, which has the largest health expenditure, is ranked first in responsiveness and yet had a consulting rate among those who met the criteria for a mental disorder of only $22 \%$. Canada and The Netherlands both spend half as much on health as does the USA, are ranked 8th and 9th on responsiveness and had low rates of consulting for mental problems: $22 \%$ and $32 \%$, respectively. The UK, which spends one-third of what the USA does on health, has the smallest outof-pocket component $(3 \%)$ and ranks 27 th on responsiveness, has a consulting rate among those with a mental disorder of 23-27\%. Bebbington et al (2000) reported that $34 \%$ of people identified as suffering anxiety or depression in the UK survey consulted their general practitioners about a mental problem. We used additional data 
Table 5 Prevalence of mental disorders, service utilisation, health system performance and expenditure in the USA, The Netherlands, Canada, Australia and the UK

\begin{tabular}{|c|c|c|c|c|c|c|c|c|c|}
\hline \multirow[t]{2}{*}{ Country } & \multicolumn{2}{|c|}{ Prevalence and service use } & \multicolumn{4}{|c|}{ Health system performancel } & \multicolumn{3}{|c|}{ Health expenditure } \\
\hline & $\begin{array}{c}12 / 12 \\
\text { prevalence } \\
(\%)\end{array}$ & $\begin{array}{c}12 / 12 \\
\text { consults }^{2} \\
(\%)\end{array}$ & $\begin{array}{l}\text { DALE } \\
\text { (Rank) }\end{array}$ & $\begin{array}{c}\text { Responsiveness } \\
\text { (Rank) }\end{array}$ & $\begin{array}{l}\text { Fairness } \\
\text { (Rank) }\end{array}$ & $\begin{array}{c}\text { Overall } \\
\text { performance } \\
\text { (Rank) }\end{array}$ & $\begin{array}{c}\text { Total health } \\
\text { expenditure } \\
\text { (Int. \$) }\end{array}$ & $\begin{array}{l}\text { OOP } \\
(\%)\end{array}$ & $\begin{array}{l}\text { Expenditure } \\
\text { as \% of GDP }\end{array}$ \\
\hline USA & 29 & 22 & 24 & $\mathrm{I}$ & 54.5 & 37 & 3724 & 17 & 13.7 \\
\hline Canada & 20 & 22 & 12 & 7.5 & 18 & 30 & 1836 & 17 & 8.6 \\
\hline Australia & 23 & 33 & 2 & 12.5 & 27.5 & 32 & 1601 & 17 & 7.8 \\
\hline UK & 24 & $\sim 25$ & 14 & 26.5 & 9.5 & 18 & 1193 & 3 & 5.8 \\
\hline
\end{tabular}

DALE, disability-adjusted life expectancy; Int. \$, international \$ (see World Health Organization, 2000); OOP, out-of-pocket expenditure.

I. Rankings are from the World Health Organization (2000).

2. Percentages represent the proportion of people with a mental disorder who had at least one consultation with any health professional for mental health problems over a 12 -month period.

to calculate pro rata values for all people with mental disorders. These data, together with data from Australia, are shown in Table 5, and no obvious lessons emerge. The USA spends the most on health care (in dollars and as a proportion of the gross domestic product), ranks first for responsiveness and yet only $22 \%$ of those with mental disorder consulted. The UK spends the least on health care, ranks poorly on responsiveness, has the least out-of-pocket expenditure and has a consultation rate that differs little from the USA. System variables do not seem to influence the met need.

\section{Consultations and illness type}

People with psychosis have greatest contact with the health services (Jablensky et al, 2000 ) and then there is a hierarchy, from affective disorders to substance use disorders, over which the probability of consulting is reduced sixfold.

\section{Consultations and demographic variables}

Howard et al (1996) reanalysed the data from the US Epidemiologic Catchment Area Program, Katz et al (1997) reviewed the results of the matched US National Comorbidity Survey and the Ontario Health Survey, Bebbington et al (2000) analysed the treatment of anxiety and depression from the UK national survey and all, like the present survey, found that only one group - educated women of child-rearing age-consult appropriately. The other demographic groups underconsult, with school-only-educated males without family responsibilities consulting least. Some of this underconsulting in males is because they do not recognise that they have an emotional problem (Kessler et al, 1981) but the specific age and gender relationship is such a consistent finding across all studies that we wonder if there could be an overriding explanation. Elsewhere, others (Jorm, 2000) have argued for better mental health literacy for the general population, and now we argue that it should be specifically targeted at these males.

Breast cancer is a field that has made radical advances by four concurrent strategies: identifying risk factors, using targeted population screening, producing widespread public understanding and professionwide acceptance of management guidelines. The mental health field could do likewise. Identification of risk factors and targeted screening are now possible, but coverage and compliance depend on good public understanding of mental disorders and of the importance of appropriate treatment. Understanding is poor and remedial action is required, perhaps along the lines already begun by websites such as http://www. rcpsych.ac.uk or http://www.crufad.org. The requirement of profession-wide acceptance of management guidelines seems difficult to obtain (Andrews, 1999). We would estimate that although one in five got appropriate treatment, fewer would comply and benefit. It is no wonder that the burden of mental disorders remains high.

General practitioners and specialists are overwhelmed by the thought that they should treat all people disabled by a mental disorder. If everyone did consult, practitioners indeed would be overwhelmed. But if we implemented the four strategies identified in the breast cancer literature, then the number consulting would be reduced by prevention and self-help strategies, and the number becoming chronic and needing continual help would be reduced by effective treatment. Then the burden of mental disorder might lessen, and demand and supply might balance.

\section{ACKNOWLEDGEMENTS}

This paper was supported by a contract from the Australian Department of Health and Aged Services to the WHO Collaborating Centre for Mental Health, Sydney, to fund a survey data analysis consortium (G. Andrews, V. Carr, G. Carter, R. Crino, W. Hall, A. Henderson, I. Hickie, C. Hunt, L. Lampe, J. McGrath, A. McFarlane, P. Mitchell, L. Peters, M. Teesson, K.Wilhelm). The survey was conducted by the Australian Bureau of Statistics, who do not necessarily endorse the views expressed in this paper.

\section{REFERENCES}

Alegria, M., Bijl, R.V., Lin, E., et al (2000) Income differences in persons seeking outpatient treatment for mental disorders. Archives of General Psychiatry, 57, 383-391.

American Psychiatric Association (1994) Diagnostic and Statistical Manual of Mental Disorders (4th edn) (DSM-IV). Washington, DC: APA.

Andrews, G. (1999) Randomised controlled trials in psychiatry: important but poorly accepted. British Medical Journal, 319, 562-564.

\& Henderson, S. (2000) Unmet Need in Psychiatry. Cambridge: Cambridge University Press.

— \& Peters, L. (1998) Psychometric properties of the CIDI. Social Psychiatry and Psychiatric Epidemiology, 33, $80-88$

_, Sanderson, K., Slade, T., et al (2000) Why does the burden of disease persist? Relating the burden of anxiety and depression to effectiveness of treatment. Bulletin of the World Health Organization, 78, 446-454.

—, Henderson, S. \& Hall, W. (200I) Prevalence, comorbidity, disability and service utilisation. Overview 
of the Australian National Mental Health Survey. British Journal of Psychiatry, 178, 145-153.

Bebbington, P., Meltzer, H., Brugha, T., et al (2000) Unequal access and unmet need: neurotic disorders and the use of primary care services. Psychological Medicine, 30, 1359-1368.

Carter, G. (1998) Service Utilisation Development for the Australian Survey of Mental Health and Wellbeing. Newcastle, NSW: University of Newcastle.

Cooper, L., Peters, L. \& Andrews, G. (1998) Validity of the Composite International Diagnostic Interview (CIDI) psychosis module in a psychiatric setting. Journal of Psychiatric Research, 32, 361-368.

Eysenck, S. B. G., Eysenck, H. J. \& Barrett, P. A. (1985) A revised version of the psychoticism scale. Personality and Individual Differences, 6, 21-29.

Gould, R. A. \& Clum, G. A. (1993) A meta-analysis of self-help treatment approaches. Clinical Psychology Review, 13, 169-186.

Howard, K. I., Cornille, T. A., Lyons, J. S., et al (1996)

Patterns of health service utilization: special article. Archives of General Psychiatry, 53, 696-703.

Jablensky, A., McGrath, J., Herrman, H., et al (2000)

Psychotic disorders in urban areas. Australian and New Zealand journal of Psychiatry, 34, 221-236.

Jorm, A. F. (2000) Mental health literacy. Public knowledge and beliefs about mental disorders. British Journal of Psychiatry, 177, 396-40I.

Katz, S. J., Kessler, R. C., Frank, R. G., et al (1997) Mental health care use, morbidity and socioeconomic status in the United States and Ontario. Inquiry, 34 $38-49$

Kessler, R. C., Brown, R. L. \& Broman, C. L. (198I) Sex differences in psychiatric help seeking: evidence from four large scale surveys. Journal of Health and Social Behavior, 22, 49-64.

Kish, L. \& Frankel, M. R. (1974) Inference from complex samples. Journal of the Royal Statistical Society, Series $B, \mathbf{3 6}, 1-37$.

Meadows, G., Harvey, C., Fossey, E., et al (2000) Assessing perceived need for mental health care in a community survey: the development of the Perceived Need for Care Questionnaire (PNCQ). Social Psychiatry and Psychiatric Epidemiology, 35, 427-435.

Murray, J. L. \& Lopez, A. d. (1996) The Global Burden of Disease. Boston: World Health Organization.

\section{CLINICAL IMPLICATIONS}

- Differences in health systems do not explain the low rates of consulting for mental disorders across several countries.

- Health services need to focus on attitudinal and not structural barriers to care.

- Coverage, competence and compliance could be increased through the identification of risk factors, use of self-help and prevention strategies, public education and management guidelines.

\section{LIMITATIONS}

Diagnostic and health service utilisation data and information on respondents' most clinically significant mental disorder are based on self-report.

- Service use for specific disorders as against mental health problems in general is not identified directly.

- Service use for psychosis and cognitive impairment is not a focus.

GAVIN ANDREWS, FRCPsych, CATHY ISSAKIDIS, BA (Hons), World Health Organization Collaborating Centre, School of Psychiatry, UNSW at St Vincent's Hospital, Sydney, Australia; GREG CARTER, FRANZCP, Faculty of Medicine and Health Sciences, University of Newcastle, NSW, Australia

Correspondence: Professor Gavin Andrews, The University of New South Wales, School of Psychiatry, Clinical Research Unit for Anxiety Disorders, 299 Forbes Street, Darlinghurst, New South Wales 2010, Australia.E-mail: gavin@crufad.unsw.edu.au

(First received 2 January 200I, final revision 23 April 200I, accepted 26 April 200I)

Nathan, P. E. \& Gorman, J. M. (1998) A Guide to Treatments That Work. Oxford: Oxford University Press.

Shah, B. V., Barnwell, B. G. \& Biegler, G. S. (1997) SUDAAN User's Manual. Research Triangle Park, NC: Research Triangle Institute.

Slade, T., Peters, L., Schneiden, V., et al (1998)

The International Personality Disorder Examination Questionnaire (IPDEQ): preliminary data on its utility as a screener for anxious personality disorder. International Journal of Methods in Psychiatric Research, 7, 84-88.

Ware, J. E., Kosinski, M. \& Keller, S. D. (1996) A 12-item short form health survey. Medical Care 34, 220-233.

World Health Organization (2000) The World Health Report 2000. Health Systems: Improving Performance. Geneva: WHO. 